\title{
Pemphigus vulgaris in pregnancy with transient neonatal pemphigus - can psychological stress be culprit?
}

\author{
Nisha Bhagat ${ }^{1 *}$, Rajnish Raj ${ }^{2}$, Ritu Arora ${ }^{3}$
}

\begin{abstract}
${ }^{1}$ Department of Obstetrics and Gynecology, Government Medical College, Amritsar, Punjab, India
${ }^{2}$ Department of Psychiatry, Government Medical College, Patiala, Punjab, India

${ }^{3}$ Department of Pathology, North Delhi Municipal Corporation Medical College and Hindu Rao Hospital, New Delhi, India
\end{abstract}

Received: 17 July 2017

Accepted: 18 August 2017

\section{*Correspondence:}

Dr. Nisha Bhagat,

E-mail: nishabhagat07@yahoo.com

Copyright: () the author(s), publisher and licensee Medip Academy. This is an open-access article distributed under the terms of the Creative Commons Attribution Non-Commercial License, which permits unrestricted non-commercial use, distribution, and reproduction in any medium, provided the original work is properly cited.

\begin{abstract}
Pemphigus vulgaris (PV) is a rare life threatening, autoimmune bullous disease affecting mucous membrane and skin. Pregnancy and emotional stress may be the possible triggering factors for PV. It is a very rare phenomenon with less than 27 cases of pregnancy induced PV and only 9 cases of neonatal pemphigus reported in literature. The lesions may appear transient in neonate which resolve spontaneously over 2-3 weeks. We hereby, report a case of 26-year-old female who developed PV in second trimester of pregnancy with peripartum depression, which was managed by intravenous, oral and topical steroids and selective-serotonin reuptake inhibitor (SSRI). Furthermore, the development of transient neonatal pemphigus raises the possibility of genetic linkage from maternal to fetal transmission.
\end{abstract}

Keywords: Corticosteroids, Pemphigus vulgaris, Peripartum depression

\section{INTRODUCTION}

Pemphigus vulgaris (PV) is a very rare, chronic, autoimmune bullous disease characterized by widespread blistering and erosions distributed typically on mouth, groin, scalp, face, neck, axilla and genitalia. ${ }^{1}$ The disease affects all races (though Jews are more susceptible) and both sexes, appears in the middle age and rarely affects children. ${ }^{2}$ It is common in eastern countries like India, Malaysia, and China and rare in western world. ${ }^{3}$ A recent study from the United Kingdom has suggested an incidence of PV of 0.68 cases per 100,000 persons per year. ${ }^{4}$ Genetic factors and psychological stress play an important role in its predisposition. In fact, a clinical investigation of 13 consecutive pemphigus patients with personality disorders revealed that 12 of them had experienced a stressful event during the year preceding the onset of the immune disorder. ${ }^{5,6}$ Pregnancy also acts as a triggering factor of pemphigus vulgaris (PV) and reported to be a rare phenomenon. ${ }^{7} \mathrm{PV}$ may result in abortion, fetal growth retardation, intrauterine death, premature delivery, and in approximately $30 \%$ of the pregnant women had neonatal PV. ${ }^{8}$ Lin et al., found 26 patients with pemphigus diagnosed during pregnancy between 1966 and 2013 with 9 neonates developing PV. ${ }^{9}$ Steroids and immunosuppressive agents along with supportive therapy is the mainstay of treatment although it may have deleterious effect on fetus. We hereby, report a case of pregnancy and stress induced PV in a 26-yearold female with peripartum depression and transient neonatal pemphigus.

\section{CASE REPORT}

A 26-year-old female, G2P1L1, presented in Out Patient Department (OPD) of Obstetrics and Gynecology, Government Medical College, Amritsar with 28 weeks 
period of gestation having chief complaints of multiple oral lesions for 4 months and multiple vesicular, bullous lesions over whole body for the last 2 months. She developed multiple erosions in oral mucosa associated with difficulty in chewing and burning sensation on eating spicy food. Two months ago, a single vesicle filled with clear fluid appeared over abdomen which ruptured spontaneously within the next 3 days leaving behind painful ulcer associated with burning and pruritis. Similar lesions appeared over upper chest, abdomen, back, arms and legs in that order during the next 15 days. There was no past or family history of the disease. Skin specialist consultation was taken. She took treatment in the form of antihistaminic, calamine lotion, corticosteroids but got partial relief. She reported sadness of mood, crying spells, lethargy, restlessness, palpitation, sweating and decreased sleep for the last $1^{1 / 2}$ months. There was no past history of any mood disorder, neither it was precipitated by any substance eg., steroids or diabetes, hyper or hypothyroidism. Family history for any medical or psychiatric illness was negative. Psychiatric consultation was sought. On mental status examination, she was conscious, well oriented to time, place and person. Her speech was normal in rate, rhythm and volume. She was sad, affect was appropriate to mood content, normal in range. Thought content, process and perception; higher mental function, Judgment, insight and contact with the reality were normal. Diagnostic and Statistical Manual of Mental Disorder (DSM-5) revealed a clinical diagnosis of 309.21 (F43.21) Adjustment disorder specifier: with depressive mood. ${ }^{10}$ Subsequently, severity was assessed on Hospital Anxiety and Depression Scale-Anxiety (HADS-A) and Hospital Anxiety and Depression Scale-Depression (HADS-D); Clinical outcome on Clinical Global Impression-Severity Scale (CGI-S) having scores of 13, 11 and 4 respectively. ${ }^{11,12}$

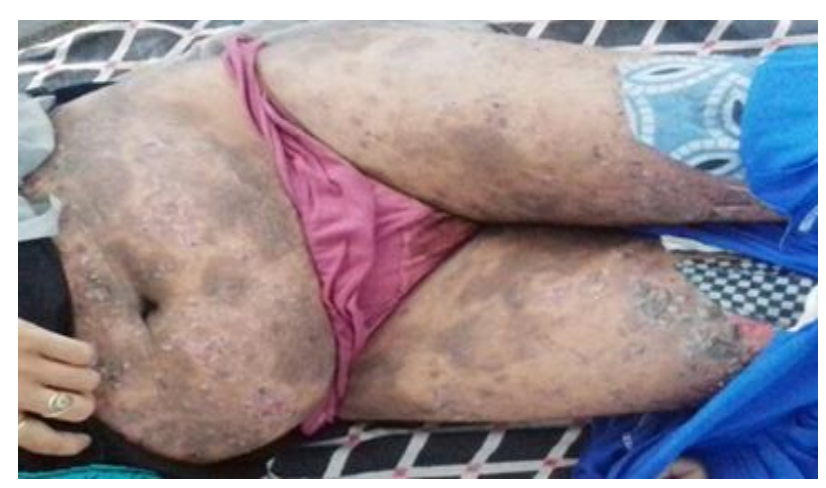

Figure 1: Crusted plaques and erosion on front of abdomen and thighs.

On general physical examination, there was edema of the hands and feet with mild dehydration but no fever, pallor, jaundice or cyanosis. Systemic examination was normal. Cutaneous examination revealed, lesions over body in the form of multiple vesicles and bullae filled with clear fluid with size ranging from $0.2 \mathrm{~cm} \mathrm{x} 0.6 \mathrm{~cm}$ to $2 \mathrm{~cm} \times 3 \mathrm{~cm}$ with well-defined irregular margins. There were multiple erosions with crust on legs of sizes $1 \mathrm{~cm} \mathrm{x} 2 \mathrm{~cm}$ to $6 \mathrm{~cm} \mathrm{x}$ $7 \mathrm{~cm}$ (Figure 1).

Mucosal lesions were in form of multiple erosions over buccal mucosa and labia minora with well-defined margins. Palms, soles and scalp were spared. Nikolsky's sign was positive. Tzanck smear showed typical acantholytic cells (Figure 2).

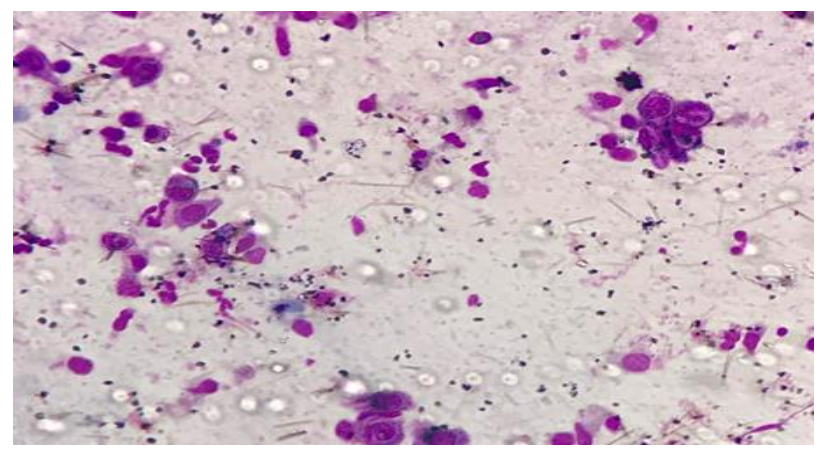

Figure 2: Tzanck smear showing typical acantholytic cells $($ MGG $\times$ 400).

Haemogram and routine investigations were normal, ESR was raised. Ultrasound abdomen showed single live fetus of 28 weeks gestation, with no fetal anomalies, vertex presentation with posterior placenta and adequate liquor.

A skin biopsy taken from a bulla showed intraepidermal bullae in suprabasal location containing acantholytic cells which was consistent with the diagnosis of PV (Figure 3).

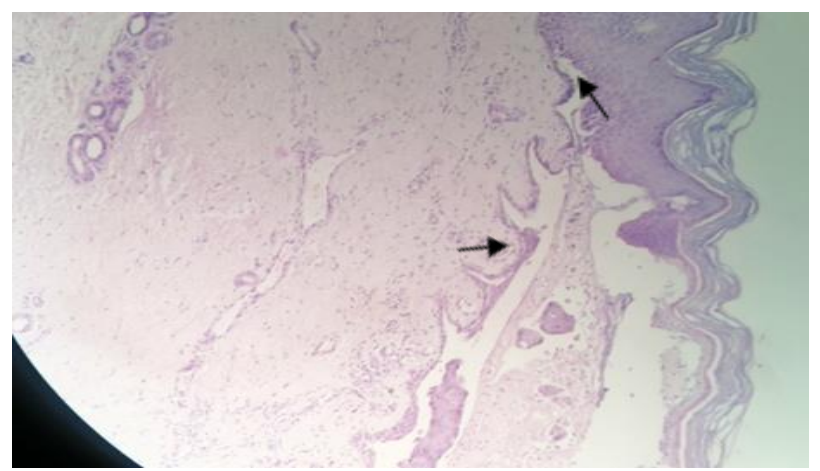

Figure 3: Photomicroograph showing bulla in suprabasal location (arrow upward) with acantholytic cells (arrow horizontal) (H and $\mathrm{E} \times 100)$.

The patient was diagnosed as pregnancy induced PV with peripartum depression, got admitted and treated with infusion of Methylprednisolone hemisuccinate (single dose $500 \mathrm{mg} \mathrm{i} / \mathrm{v}$ ) and oral therapy of Prednisone 60 $\mathrm{mg}$ /day after explaining the potential harmful effects to the fetus. Prednisolone was given for 2 weeks along with antibiotics (Azithromycin $500 \mathrm{mg}$ per day for five days) and supportive therapy. Subsequently, the dose was reduced to half and finally patient was discharged with 30 $\mathrm{mg}$ Prednisolone per day in divided doses as the isease was under control. 
These symptoms could be in response to the perceived stress of pregnancy with PV. There was no previous history of any precipitation of peripartum PV neither it could be attributed to drug nor to premorbid anxious personality "state or trait" of the patient because of her low level scores i.e., 27 and 35 on State and Trait Anxiety Inventory (STAI). ${ }^{13}$

After 4 weeks of treatment with escitalopram $10 \mathrm{mg}$ per day, her HADS-A, HADS-D and Clinical Global Impression- Improvement Scale (CGI-I) scores were 6, 9 and 1 respectively, indicating very much improvement.

Later on patient delivered a full term single, alive female baby at 38 weeks through vaginal route. The neonate had impetigo over the cheek and biopsy proven PV over nape of neck and inner side of both lower legs (Figure 4, 5, 6).

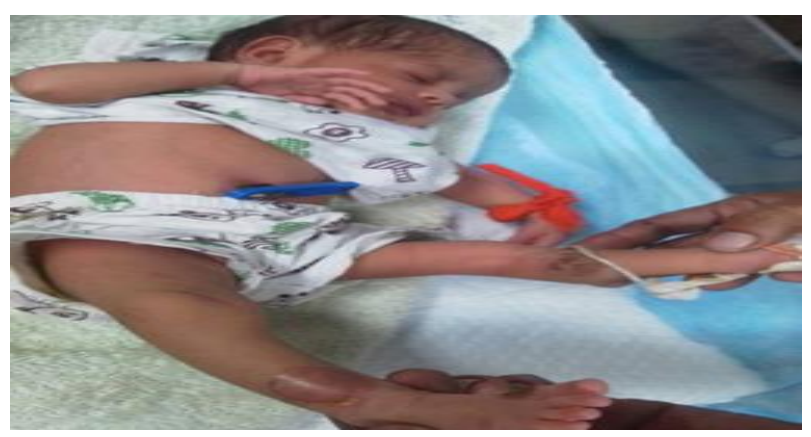

Figure 4: Ruptured bulla and crusted plaques on both legs.

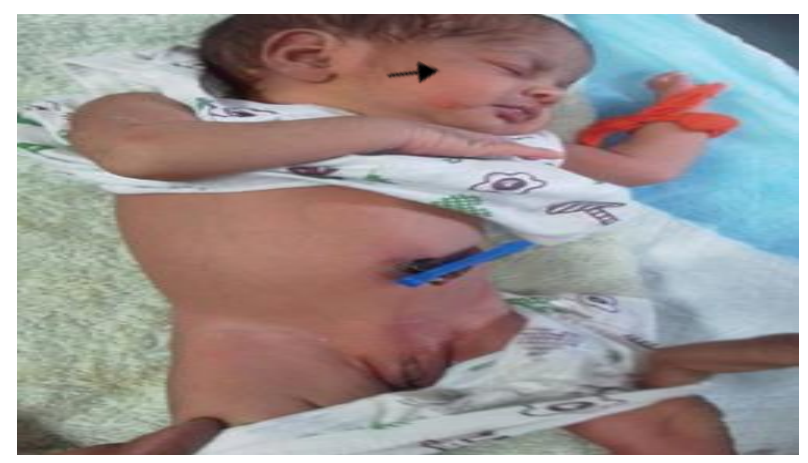

Figure 5: Impetigo on the cheek.

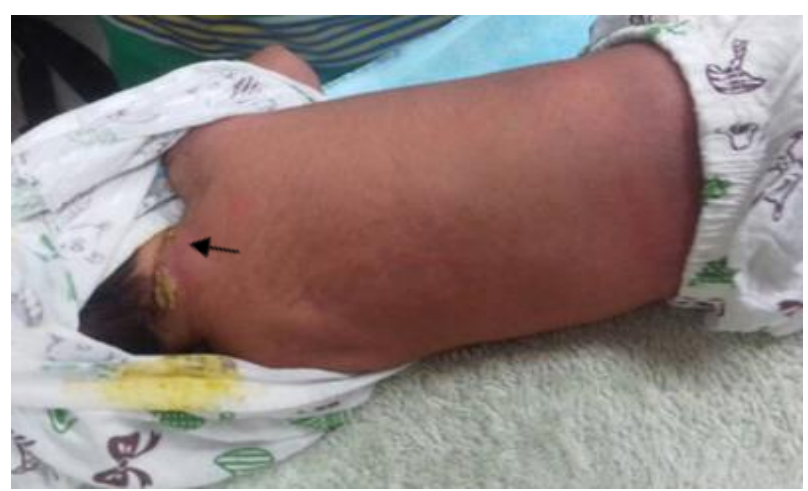

Figure 6: Pemphigus vulgaris on the nape.
The lesions cleared over 2 weeks with topical steroids. The patient on follow-up reported that her child to be completely healthy. Both her skin and mucous membranes were free from any lesions.

\section{DISCUSSION}

Pemphigus vulgaris (PV) is the most frequent form of the pemphigus. It is a prototypical organ-specific human autoimmune disorder with a poor prognosis in the absence of medical treatment. The patho-physiological mechanism is linked to the presence of auto-antibodies directed against desmoglein-3, desmosome transmembrane glycoprotein that belonged to the cadherin family which lead to cell-cell detachment (acantholysis) in deep part of epithelium just above the basal layer (suprabasal acantholysis) and resulted in splitting that gives rise to blister formation (intraepithelial bulla). ${ }^{14}$

The precipitating factors are many and most of them directly originating from the environment which includes drug intake, viral infections especially herpetic, physical agents (ultraviolet or ionizing radiation, thermal or electrical burns, surgery and cosmetic, contact allergens), diet, others being endogenous like emotional stress, hormonal disorders but somehow linked with the subject's lifestyle and personality. ${ }^{15-19}$

Diagnosis is made by Tzanck smear, immunoflurescent studies (direct and indirect) and biopsy of the lesion. Pregnancy was recognized as a trigger of pemphigus, or only a factor of exacerbation. ${ }^{20,21}$ Our case belonged to the former category. The disease is aggravated most likely during the first, second trimester and during postpartum; then relived during the third trimester. ${ }^{22}$ This may be due to the increased level of endogenous corticosteroid hormone from chorion and causes subsequent immune suppression.

The role of psychological stress in triggering PV is still underestimated and, in most cases of apparently spontaneous PV, both patient and doctor overlook the intervention of an emotional precipitating factor. Studies have shown that stress can play a triggering part in pemphigus apart from any underlying personality disorders. Matias et al., reviewed 9 published works of stress leading to pemphigus. ${ }^{23}$ In our case, emotional and pregnancy associated stress may have role in developing PV.

PV in pregnancy may result in abortion, fetal growth retardation, intrauterine death, premature delivery, and in approximately $30 \%$ neonatal PV of the newborns as reviewed by Daneshpazhooh et al. Transplacental transmission of PV IgG antibodies from mother to fetus may result in clinical manifestations in the neonate. The lesions are transient and heal spontaneously within 2-3 weeks without any untoward effect on baby. In our case neonate too had transient lesions but it got completely cured by local steroids in 2 weeks. 
In almost all types of pemphigus, patients experience severe worsening of the disease after delivery if there is inadequate control of disease during pregnancy. The current study suggested systemic glucocorticoids as the first line of treatment, alone or in combination with other immunosuppressive agents such as Azathioprine and Cyclosporine, intravenous immunoglobulin ( $\mathrm{IgG})$ or plasmapheresis. ${ }^{24}$ If the disease worsens during the first trimester, medical termination of pregnancy may be considered, and if it happens during the second and third trimester, it is recommended to use aggressive topical therapy. ${ }^{25}$ There is moderate evidence suggestive of an effective and safe effect of $\mathrm{IgG}$ as an auxiliary therapy in pregnant patients with pemphigus. ${ }^{26}$ Therefore, when pregnancy is associated with significant medical problems or disease states, clinicians should consider IgG. Plasmapheresis is another alternative immunosuppressive therapy in pregnancy, which can be used as adjuvant therapy with systemic corticosteroids. ${ }^{27}$ Our patient responded well to oral and topical corticosteroids along with psychotherapy.

Regarding mode of delivery, Goldberg and Fainaru in their studies indicated that the trauma of vaginal delivery can result in extension and deterioration of the wound. ${ }^{28,29}$ In a cesarean section, patients who receive long-term steroid therapy will increase the risk of disease itself and corticosteroids may complicate wound healing. Therefore, except for obstetric contraindications, vaginal delivery is recommended.

\section{CONCLUSION}

PV in pregnancy can be life threatening and aggressive treatment approach is required to control disease in pregnant women and achieving good neonatal outcomes. In summary, pemphigus and pregnancy is still an indistinct area that needs collaborative work by obstetricians, dermatologists, neonatologists, psychiatrists and medical specialists to establish multi-disciplinary treatment approach.

\section{Funding: No funding sources}

Conflict of interest: None declared

Ethical approval: Not required

\section{REFERENCES}

1. Amagai M, Pemphigus. In: Dermatology (Bolognia J L, Jorizzo J, Rapini R P eds). London: Mosby. 2003: 449-62.

2. Joly P, Litrowski N. Pemphigus group (vulgaris, vegetans, foliaceus, herpetiformis, brasiliensis). Clin Dermatol. 2011;29:432-6.

3. Nandini G, Umadevi K, Padma K, Rajini Uday, Sahana R. Pemphigus Vulgaris with pregnancy. J South Asian Fed Obstet Gynaecol. 2012;4(3);159-60.

4. Langan SM, Smeeth L, Hubbard R, Fleming KM, Smith CJ, West J. Bullous pemphigoid and Pemphigus vulgaris. Incidence and mortality in the
UK: population based cohort study. BMJ. 2008;337:180.

5. Firooz A, Mazhar A and Ahmed AR. Prevalence of autoimmune diseases in the family members of patients with Pemphigus vulgaris. J Am Acad Dermatol. 1994;31:434-7.

6. Cremniter D, Baudin M, Roujeau JC. Stressful life events as potential triggers of pemphigus. Arch Dermatol. 1998;134:1486-7.

7. Bialynicki-Birula R, Dmochowski M, Maj J, Gornowicz-Porowska J. Pregnancy-triggered maternal pemphigus vulgaris with persistent gingival lesions. Acta Dermatovenerol Croat. 2011;19:170-5.

8. Daneshpazhooh M, Chams-Davatchi C, Valikhani M, Aghabagheri A, Mortazavizadeh SM, Barzegari $M$ et al. Pemphigus and pregnancy: a 23-year experience. Indian J Dermatol Venereol Leprol. 2011;77:534.

9. Lin L, Zeng X, Chen Q. Pemphigus and pregnancy: Analysis and summary of case reports over 49 years. Saudi Med Journal. 2015;36(9):1033-8.

10. American Psychiatric Association. Diagnostic and Statistical manual of mental disorders, 5th ed., Washington DC: American Psychiatric Association. 2013.

11. Bjelland I, Dahl AA, Haugg TT, Neckelmann D. The validity of the hospital Anxiety and Depression Scale: an update literature review. J Psychosom Res. 2002;52:69-77.

12. Beneke $\mathrm{M}$ and Rasmus W. Clinical global impressions (ECDEU): some critical comments. Pharmacopsychiatrie.1992;25:171-6.

13. Spielberger CD, Gorsuch RL, Lushene PR, Vagg PR and Jacobs GA. Manual for State-Trait Anxiety Inventory: Bibliography ( $2^{\text {nd }}$ ed) Palo Alto, CA: Consulting Psychologists Press; 1983.

14. Ruocco V, Ruocco E, Schiavo AL, Brunetti G, Guerrera LP, Wolf R. Pemphigus: Etiology, pathogenesis, and inducing or triggering factors: Facts and controversies. Clin Dermatol. 2013;31(4): 374-8.

15. Ruocco V, de Angelis E, Lombardi ML. Druginduced pemphigus. II. Pathomechanisms and experimental investigations. Clin Dermatol. 1993; 11:507-13.

16. Caldarola G, Kneisel A, Hertl M, Feliciani C. Herpes simplex virus infection in pemphigus vulgaris: clinical and immunological considerations. Eur $\mathbf{J}$ Dermatol. 2008;18:440-3.

17. Ruocco V, Ruocco E. Pemphigus and environmental factors. G Ital Dermatol Venereol. 2003;138:299309.

18. Ruocco V, Brenner S, Ruocco E. Pemphigus and diet: does a link exist? Int J Dermatol. 2001;40:1613.

19. Morell-Dubois S, Carpentier O, Cottencin O. Stressful life events and pemphigus. Dermatology. 2008;216:104-8. 
20. Muhammad JK, Lewis MA, Crean SJ. Oral pemphigus vulgaris occurring during pregnancy. J Oral Pathol Med. 2002;31:121-4.

21. Schmutz JL. Dermatological diseases influenced by pregnancy. Presse Med. 2003;32:1809-12.

22. Kalayciyan A, Engin B, Serdaroglu S, Mat C, Aydemir EH, Kotogyan A. A retrospective analysis of patients with pemphigus vulgaris associated with pregnancy. Br J Dermatol. 2002;147:396-7.

23. Matias $\mathrm{AB}$ and Roselino AMF. Pemphigus and psychological stress: a review of the literature. Our Dermatol Online. 2013;4(S3):616-8.

24. Mimouni D, Nousari CH, Cummins DL, Kouba DJ, David M, Anhalt GJ. Differences and similarities among expert opinions on the diagnosis and treatment of Pemphigus vulgaris. J Am Acad Dermatol. 2003;49:1059-62.

25. Kanwar AJ, Thami GP. Pemphigus vulgaris and pregnancy-a reappraisal. Aust N Z J Obstet Gynaecol. 1999;39:372-3.

26. Gurcan HM, Jeph S, Ahmed AR. Intravenous immunoglobulin therapy in autoimmune mucocutaneous blistering diseases: a review of the evidence for its efficacy and safety. Am J Clin Dermatol. 2010;11:315-26.

27. Shieh S, Fang YV, Becker JL, Holm A, Beutner EH, Helm TN. Pemphigus, pregnancy and plasmapheresis. Cutis. 2004;73:327-9.

28. Goldberg NS, DeFeo C, Kirshenbaum N. Pemphigus vulgaris and pregnancy: risk factors and recommendations. J Am Acad Dermatol. 1993;28(5.2):877-9.

29. Fainaru O, Mashiach R, Kupferminc M, Shenhav M, Pauzner D, Lessing JB. Pemphigus vulgaris in pregnancy: a case report and review of literature. Hum Reprod. 2000;15:1195-7.

Cite this article as: Bhagat N, Raj R, Arora R. Pemphigus vulgaris in pregnancy with transient neonatal pemphigus - can psychological stress be culprit? Int J Reprod Contracept Obstet Gynecol 2017;6:4703-7. 